\title{
Examination of the apoptotic effects of betulinic acid on renal cancer cell lines
}

\author{
Arzu ERGEN $^{1}$ (D), E. Sinem IPLIK ${ }^{(\mathbb{D})}$, Baris ERTUGRUL ${ }^{1}$ (D), Merve Nur ATAS ${ }^{1}$ (D), Goksu KASARCI ${ }^{1}$ (D), Bedia CAKMAKOGLU \\ ${ }^{1}$ Department of Molecular Medicine, Aziz Sancar Institute of Experimental Medicine, Istanbul University, Istanbul, Turkey. \\ ${ }^{2}$ Faculty of Pharmacy, Istanbul Yeni Yuzyil University, Istanbul, Turkey.
}

Corresponding Author: Arzu ERGEN

E-mail: aergen@istanbul.edu.tr

Submitted: 14.05.2020 Accepted: 23.07.2020

\section{ABSTRACT}

Objective: Renal cancers are highly resistant to standard hormonal therapy, radiotherapy, and chemotherapy, and the survival rates are extremely low. Betulinic acid is a pentasilic triterpenoid saponin of lupine type obtained from various natural plants, especially from the shell of Betula plant. Betulinic acid was shown both in in vivo, and in vitro to have the ability to induce apoptotic pathways causing no toxicity for normal cells, and also has immunomodulatory effects. The aim of the present project is to investigate the anticancer effects of betulinic acid on CAKI-2 (ATCC ${ }^{\circledR} \mathrm{HTB}^{-47^{\mathrm{mix}}}$; clear cell renal carcinoma), ACHN (ATCC $\mathrm{CRL}^{\circ} 1611^{\mathrm{mix}}$; renal cell adenocarcinoma) and MRC-5 (ATCC ${ }^{\circledR}$ CCL- $171^{\text {in: }}$ : normal lung fibroblast) cell lines.

Materials and Methods: The dose, and time-dependent cell viability was determined using the WST-1 test first in cell lines, and then apoptotic activity was determined with Annexin- $\mathrm{V}$, apoptosis related nucleosomal enrichment factor levels, and Caspase 3 / BCA activity.

Results: Betulinic acid reduced the CAKI-2, and ACHN cell viability in dose, and time-dependent manner inducing the apoptotic pathway.

Conclusion: Researchers in the present study concluded in accordance with the results of Annexin-V, apoptosis-associated nucleosomal enrichment factor levels and Caspase 3 / BCA activity that betulinic acid triggered the apoptosis in both renal cancer cell lines, especially by the Caspase 3 activity.

Keywords: Renal cancer, Betulinic acid, Apoptosis, ACHN, CAKI-2

\section{INTRODUCTION}

Triterpenoids are the metabolites of isopentenyl pyrophosphate oligomers, and constitute the largest group of natural plant products with over 20.000 known members [1]. Triterpenoids have recently received much attention owing to their various promising biological, and pharmaceutical properties, including anti-tumor, antiviral, antifungal, anti-inflammatory, and other activities [2].

Betulinic acid is a pentacyclic triterpeniod saponin of the lupane type obtained from various natural plants, in particular from the shell of the Betula plant. Betulinic acid has recently been shown to have a pronounced anti-tumoral effect in melanoma cells, and in various solid tumors, including glioblastoma, lung carcinoma, colorectal carcinoma, breast carcinoma, and prostate carcinoma [3]. Betulinic acid is different than the other known anti-tumor drugs such as doxorubicin. It is a member of a new class of potential anticancer drugs that have the ability to induce apoptosis by directly affecting the mitochondria [4-6]. Betulinic acid therapy inhibits Nuclear Factor kappa-light-chain-enhancer of activated B cells (NF-kB) activation by different stimulants in colon cancer, and lung adenocarcinoma cells. These properties of betulinic acid can be used as a starting point to prevent cancer [7]. The cytotoxicity, and anti-tumor properties of betulinic acid and its derivatives have been investigated using xenograft mouse models, as well as in many human tumor cell lines [8-10]. The efficacy of Menyanthes trifoliate-L derivatives including betulinic acid on stage IV glioblastoma cell line was investigated in a recent study, and was shown to have an effect on Bcl-2-associated X protein (Bax), B-cell lymphoma 2 (Bcl-2), caspase-3 (Cas-3), and tumor protein 53 (p53) gene expression levels, and decreased the mitochondrial membrane potential [11]. The combination of various chemotherapy agents (i.e. doxorubicin, etoposide, taxol, cisplatin, actinomycin

How to cite this article: Ergen A, Iplik E S, Ertugrul B, Atas M N, Kasarci G, Cakmakoglu B. Examination of the apoptotic effects of betulinic acid on renal cancer cell lines. Marmara Med J 2020;33(3):113-118, doi: 10.5472/marumj.815542 
$\mathrm{D}$, mitramycin $\mathrm{A}$, or vincristine) with betulinic acid induces apoptosis, and inhibits the clonogenic structure of many tumor cells [12]. In cancer treatment, all these metabolic pathways, especially the targeted ones, are the important goals in the treatment process. The Lamin 1 gene was suggested as a new therapeutic target for betulinic acid in a microarray study on pancreatic cancer [13]. The anti-cancer activity of betulinic acid was investigated in 60 drug-resistant cell lines in a single array study including ACHN and CAKI-1, one of the kidney cancer cell lines. Saeed et al., reported that betulinic acid exhibited extremely high cytotoxicity against multidrug resistant (MDR) cell lines, and the increase in MDR activity experimentally did not alter the efficacy of betulinic acid, and more importantly, the cytotoxic activity of betulinic acid was demonstrated to occur through different mechanisms. However, there was no detailed examination of the pathways where betulinic acid was effective in kidney cancer cell lines in that study [14].

It was clear in the literature that the studies on the effectiveness of betulinic acid and cancer are still popular at present, and betulinic acid is advancing confidently to be a potential drug for anti-cancer therapy. In the present study, we aimed to demonstrate the possible apoptotic efficacy of betulinic acid on renal cancer cell lines using different methods.

\section{MATERIAL and METHODS}

\section{Cell Culture}

CAKI-2 (ATCC ${ }^{\circledast}$ HTB-47 ${ }^{\text {ma }}$ ) clear cell renal carcinoma, ACHN $\left(\right.$ ATCC $^{\oplus}$ CRL-161 $^{\mathrm{mm}}$ ) renal cell adenocarcinoma isolated from the metastatic site, and a healthy cell line were prepared by growing in the cellular culture medium MRC-5 (ATCC ${ }^{\oplus}$ CCL$\left.171^{\mathrm{m}}\right)$. The media for cell lines were McCoy's medium for CAKI2, Eagle's Minimum Essential Medium (EMEM) for ACHN, and Dulbeco's Minimum Essential Medium (DMEM) for MRC5. All media were prepared with the suitable concentration of fetal bovine serum (containing 10\% FBS), and penicillin/ streptomycin as antibiotics (containing 1\%). All cells were incubated, and cultured at $37^{\circ} \mathrm{C}$ in $5 \% \mathrm{CO}_{2}$. The medium was refreshed in 2-day intervals until the cells reached to adequate count. After having the adequate confluency count, trypsin application was performed to remove cells from the flask, and then the basic cellular culture techniques were performed respectively. These experimental procedures were regularly repeated until the end of the project, approximately one year.

\section{WST-1 Cytotoxicity test}

Betulinic acid was administered at an increasing dose (1-100 $\mathrm{uM}$ ), and in increasing time intervals (24th, 48th, and $72 \mathrm{nd}$ hours). In this context, WST-1 cytotoxicity test reached the optimization stage. The experiments were repeatedly performed in order to identify the appropriate dose, and the time.

The administered doses were: $1 \mathrm{uM}, 2.5 \mathrm{uM}, 5 \mathrm{uM}, 7.5 \mathrm{uM}, 10$ $\mathrm{uM}, 25 \mathrm{uM}$, and $50 \mathrm{uM}$.
The applied time points were: 24 th, 48 th, and 72 nd hours. Cytotoxicity test was performed for each dose, and each time point.

CAKI-2, ACHN, and MRC-5 cells were seeded in 96 well plates at 10.000 cells for each well. After the application of betulinic acid, $10 \mu \mathrm{L}$ of WST- 1 solution was added to each well at the end of the incubations, and after 4 hours of incubation at $37{ }^{\circ} \mathrm{C}$, the absorbance density values of 96 well plates were measured at $440 \mathrm{~nm}$ in the enzyme-linked immunoabsorbant assay (ELISA) plate reader to determine the cell viability. Following the optimization of the cytotoxic analysis, the dose selection was done after administration of betulinic acid at increasing dose, and durations (1-100 uM; 24th, 48th, and 72nd hours).

\section{Annexin-V}

Flow cytometric Annexin-V apoptosis/necrosis analysis was performed for the quantitative determination of the dose, and time-dependent triggered apoptosis, and necrosis. Annexin-V was conjugated with fluorescein isothiocyanate (FITC) that was used in apoptosis analysis forms Annexin-V lectin, and it binds to phosphatidyl serine phospholipid located on the outer surface of the cell membrane of apoptotic cells. In combination with the 7-AAD-DNAstaining, dye exclusion of vital cells allows a discrimination between apoptotic, and necrotic cells. Cells treated in 24-well dishes were centrifuged, washed with HBSS-/- (GIBCO, Germany), and stained with $150 \mu \mathrm{L}$ of buffer containing $5 \mu \mathrm{L}$ Annexin V-FITC and $1.5 \mu \mathrm{M} 7$-AAD at $37^{\circ} \mathrm{C}$. After $10 \mathrm{~min}$, an additional $500 \mu \mathrm{L}$ of ice-cold buffer was added by the time the cells were placed on ice. After centrifugation, the cells were suspended in $250 \mu \mathrm{L}$ buffer and were immediately analysed by flow cytometry using the green-collecting fluorescent channels FL-1 for Annexin V-FITC, and FL-3 for 7-AAD, as described above. Quadrant separation in the fluorescent channels FL-1 (Annexin V-FITC) versus FL-3 (7$\mathrm{AAD})$ represents the events of necrotic, and apoptotic cells.

\section{Measurement of Apoptosis Level with Cell Death Detection Kit (Roche) in the Cell Lines}

Cell death detection kit is a photometric enzyme immunoassay used for the in vitro determination of cytoplasmic histoneassociated DNA fragments after induced cell death. Cell death levels were determined by the ELISA method in accordance with the kit instructions (Roche, USA).

\section{Analysis of Caspase 3 / BCA Activity}

Caspase activity measurement of betulinic acid-induced dose, and time-dependent apoptosis in CAKI-2, ACHN, and MRC-5 cells was performed with commercially available Caspase 3 colorimetric kit (BioVision Research Products,USA). Briefly, apoptosis-induced cells, and were collected by centrifugation at $1000 \mathrm{rpm}$ for $10 \mathrm{~min}$. Cells were lysed by adding $50 \mu \mathrm{L}$ of chilled cell lysis buffer and 
incubated on ice for $10 \mathrm{~min}$ before centrifugation at $10000 \mathrm{~g}$ for $1 \mathrm{~min}$. Supernatants were transferred to new Eppendorf tubes, and the reaction mixture was prepared in 96-well plates by adding $50 \mu \mathrm{L}$ of reaction buffer, $50 \mu \mathrm{L}$ of sample, and $5 \mu \mathrm{L}$ of DEVD-pNA substrate, and incubated at $37^{\circ} \mathrm{C}$ in $\mathrm{CO}_{2}$ incubator. After incubation, the plate was read using an ELISA reader at $405 \mathrm{~nm}$ wavelengths.

\section{Statistical Analysis}

The statistical analysis of this study was performed using the Statistical Package for the Social Sciences (SPSS) Statistics 21.0 package program, and the statistical significance limit was accepted as $\mathrm{P}<0.05$.

\section{RESULTS}

\section{WST-1 Cytotoxicity test}

CAKI-2, ACHN, and MRC-5 cells were treated with betulinic acid to calculate the percentage of viability, and the dose was determined. According to the cytotoxicity results, $25 \mathrm{uM}$ and $50 \mathrm{uM}$ betulinic acid concentrations and 24 hour incubation time were selected to continue apoptotic detection methods on the cell lines, and the experiments were continued with the selected dose, and time. In the CAKI- 2 cell line, there was a $42.6 \%$ decrease in cell viability for 24 hours, and $25 \mathrm{uM}$ dose of betulinic acid; while $84.3 \%$ reduction was detected for 24 hours at a dose of $50 \mathrm{uM}$. Cell viability in the ACHN cell line decreased by $53.5 \%$ after administration of $25 \mathrm{uM}$ betulinic acid for 24 hours; while $70.6 \%$ reduction was detected for 24 hours at a dose of $50 \mathrm{uM}(\mathrm{p}<0.05)$, there was no considerable effect of betulinic acid on viability in the healthy cell line MRC-5. The effects of betulinic acid on cell viability have been demonstrated in Figures 1, 2 and 3.

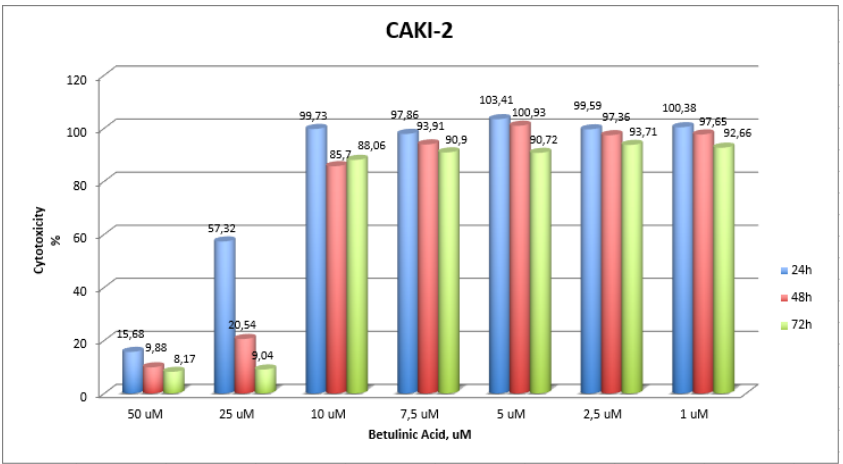

Figure 1. Effects of betulinic acid on cell cytotoxicity for CAKI-2

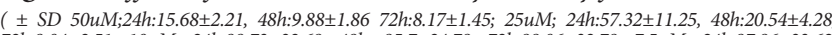

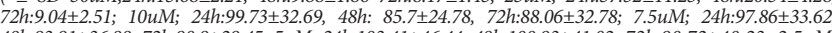
48h:93.91 $36.88,72 h: 90.9 \pm 29.45 ; 5 u M ; ~ 24 h: 103.41 \pm 46.44,48 h: 100.93 \pm 41.02,72 h: 90.72 \pm 40.23 ; 2.5 u M$ $24 h: 99.59 \pm 20.11,48 h: 87.36 \pm 23.56,72 h: 93.71 \pm 30.01 ; 1 u M ; 24 h: 100.38 \pm 24.12,48 h: 97.65 \pm 24.56$, $72 h: 92.66 \pm 18.71)$

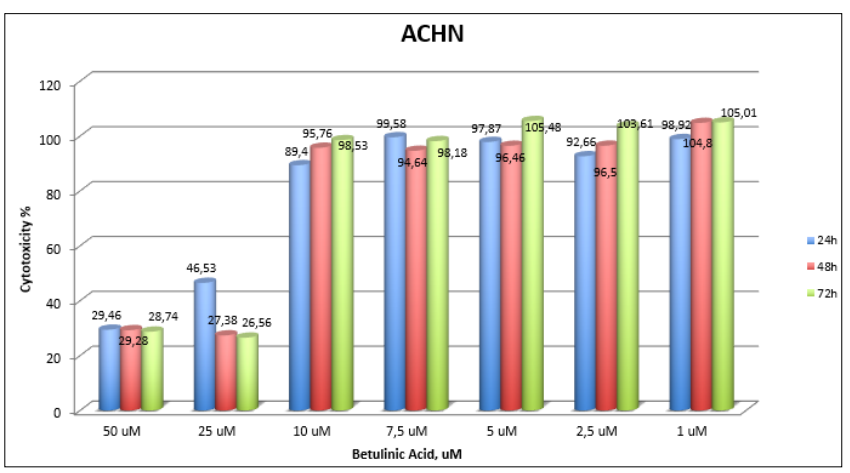

Figure 2. Effects of betulinic acid on cell cytotoxicity for ACHN

( \pm SD 50uM; $24 h: 29.46 \pm 2.29,48 h: 29.28 \pm 3.86,72 h: 28.74 \pm 1.95 ; 25 u M ; 24 h: 46.53 \pm 10.25,48 h: 27.20 \pm 4.08$,

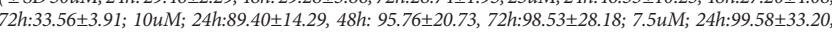
48h:94.64 $30.88, \quad 72 h: 98.18 \pm 27.44 ; \quad 5 u M ; \quad 24 h: 97.87 \pm 36.44, \quad 48 h: 96.46 \pm 40.00, \quad 72 h: 105.48 \pm 41.33$; 2.5uM; 24h:92.66 $25.10,48 h: 96.5 \pm 24.06,72 h: 103.61 \pm 33.40 ; 1 u M ; 24 h: 98.92 \pm 26.85,48 h: 104.80 \pm 31.36$,

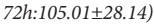

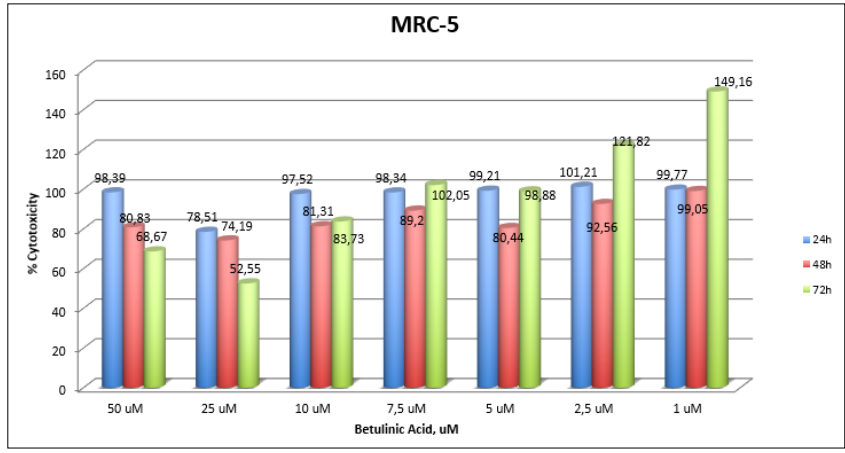

Figure 3. Effects of betulinic acid on cell cytotoxicity for MRC-5

( \pm SD 50uM; 24h: 98.39 $\pm 11.29, \quad 48 h: \quad 80.83 \pm 9.92, \quad 72 h: 88.67 \pm 21.90 ; \quad 25 u M ; \quad 24 h: 78.51 \pm 19.28$,

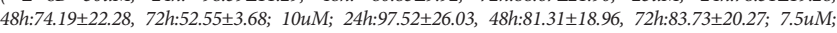
24h: $98.34 \pm 30.10, \quad 48 h: 89.20 \pm 28.11, \quad 72 h: 102.05 \pm 30.47 ; \quad 5 u M ; \quad 24 h: 99.21 \pm 27.94, \quad 48 h: 80.44 \pm 19.47$,

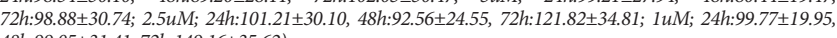
$48 h: 99.05 \pm 31.41,72 h: 149.16 \pm 35.62)$

Flow cytometric Annexin-V apoptosis/necrosis and Caspase-3/ BCA, and apoptosis-related nucleosomal enrichment factor analyses were performed in order to determine the amount of apoptosis-based cell death after administration of betulinic acid at $25 \mathrm{uM}$, and $50 \mathrm{uM}$ concentrations for 24 hours in the CAKI2, and ACHN cell lines.

\section{Annexin-V}

We performed flow cytometric Annexin-V apoptosis / necrosis analysis for quantitative determination of apoptosis, and necrosis induced by dose, and time dependent concentrations of betulinic acid at $25 \mathrm{uM}$, and $50 \mathrm{uM}$ doses, and at incubation time of 24 hours. Apoptotic cell death was observed in the ACHN cell line at a rate of $22.66 \%$ after the administration of $50 \mathrm{uM}$ of betulinic acid, while this rate was $14.25 \%$ in the CAKI-2 cell line. We found that administration of $25 \mathrm{uM}$, and $50 \mathrm{uM}$ betulinic acid had no effect on apoptosis in healthy MRC-5 cell line. The 
effects on the cell lines have been demonstrated in Figures 4, 5, and 6 .

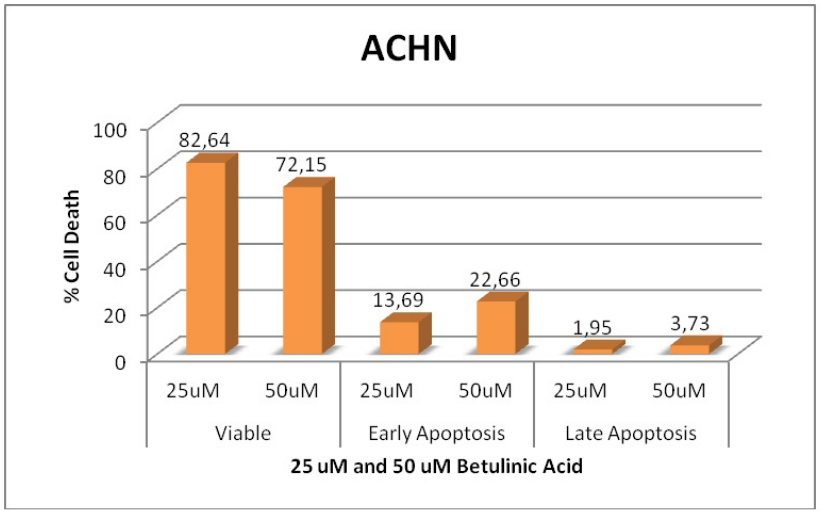

Figure 4. Annexin-V results for $A C H N$

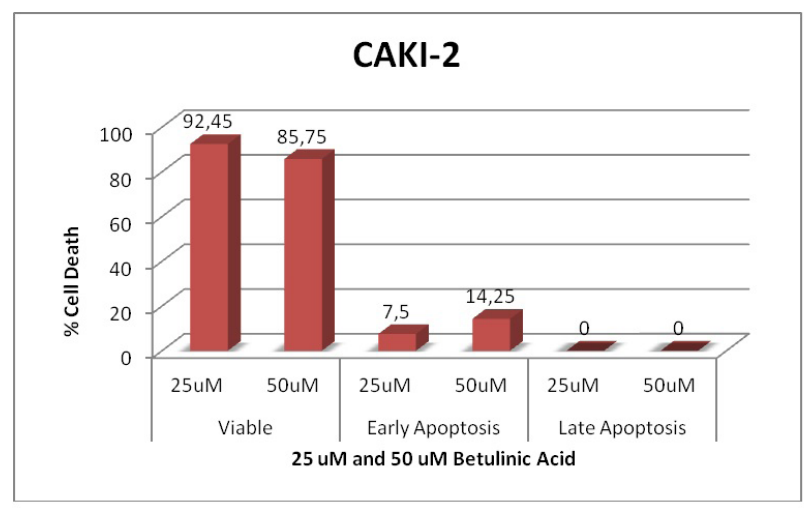

Figure 5. Annexin- $V$ results for CAKI-2

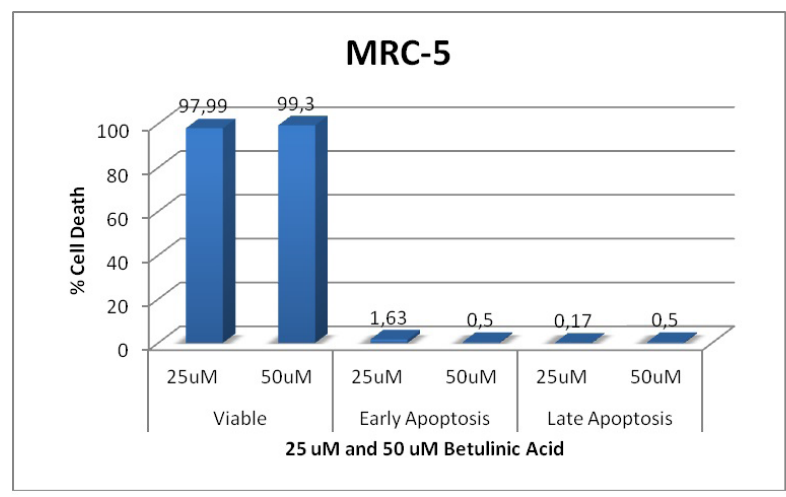

Figure 6. Annexin- $V$ results for $M R C-5$

\section{Measurement of Apoptosis Level in Cell Lines Treated with Betulinic Acid by the Determination of the Effect on Nucleosomal Enrichment Factor}

To determine the apoptotic activity of betulinic acid on CAKI2, ACHN, and MRC-5, the cells were treated with betulinic acid at selected dose, and time, and changes were detected for the nucleosomal enrichment factor. Accordingly, as a result of $25 \mathrm{uM}$ betulinic acid application, enrichment factor increased 2.33 fold in the CAKI- 2 cell line and 10.32 fold in the ACHN cell line than in MRC-5. After administration of 50 uM betulinic acid, 2.85 fold increase in the CAKI- 2 cell line, and a 2.61-fold increase in the ACHN cell line were detected (Figure 7).

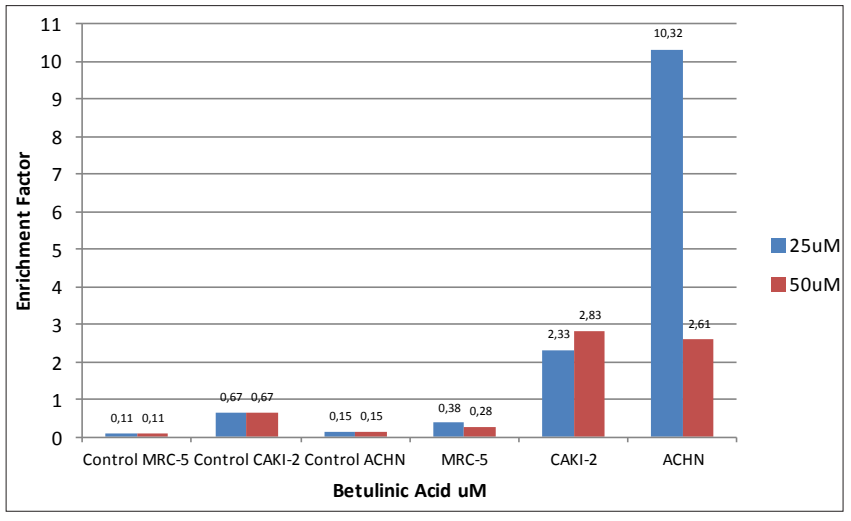

Figure 7. Effects of betulinic acid on apoptosis related nucleosomal enrichment factors

\section{Caspase 3 / BCA Activity Results}

The measurement of betulinic acid induced dose, and time dependent apoptosis in CAKI-2, ACHN, and MRC-5 cells by Caspase 3/BCA activity method showed that Caspase 3 activity increased by 1.4 -fold as a result of $25 \mathrm{uM}$ betulinic acid administration and a 1.7 -fold increase occurred by 50 $\mathrm{uM}$ administration in the CAKI-2 cell line. In the ACHN cell line, Caspase 3 activity increased 1.14-fold after $25 \mathrm{uM}$ administration, and 1.6-fold after $50 \mathrm{uM}$ administraion (P $<0.05$ ) (Figure 8).

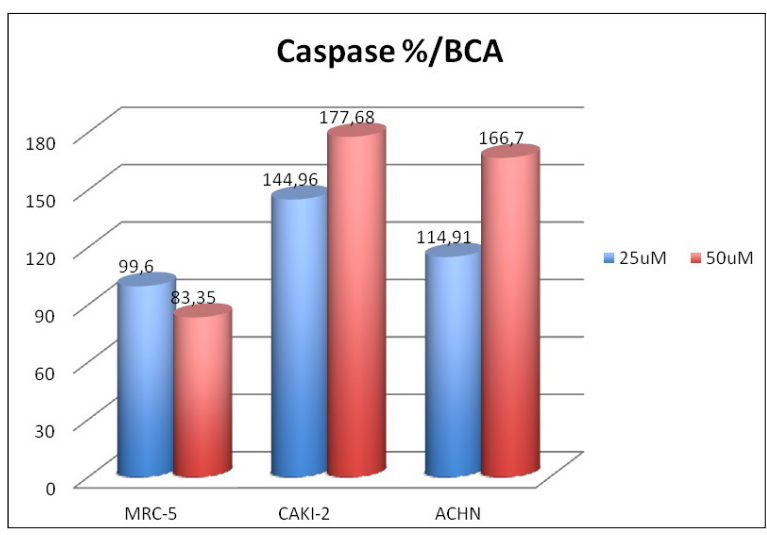

Figure 8. Effects of betulinic acid on caspase-3 activity in cell lines 


\section{DISCUSSION}

Renal cancers are highly resistant to standard hormonal therapy, radiotherapy, and chemotherapy. The average five-year survival rate is $53 \%$ in non-metastatic disease, and $8 \%$ in metastatic renal cancers. In the last 20 years, angiogenetic factors such as vascular endothelial growth factor (VEGF), platelet derived growth factor (PDGF), and mammalian target of rapamycin (mTOR) have been the main molecules for targeted treatment studies in renal cancers. Tyrosine kinase inhibitors (sunitinib, axitinib.), and mTOR inhibitors (everolimus, temsirolimus) are the drugs developed for this purpose. However, resistance against these drugs generally occurs within the first year.

Betulinic acid has potential cytotoxic effects against different cancer cells. In this experimental study, we aimed to determine the anticancer efficacy of betulinic acid in renal cancers. Therefore, Annexin-V, apoptosis-associated nuclear enrichment factor levels, and Caspase 3/BCA activity were measured following the determination of viability percentages in CAKI-2, ACHN renal cancer cell lines and the healthy cell line MRC- 5 by selecting $25 \mathrm{uM}$, and $50 \mathrm{uM}$ dose and 24-hour administration.

Zeng et al., showed in their study that betulinic acid triggered apoptosis via caspase-3 pathway in colorectal cancer cell lines, decreased the MMP gene expression level, and increased the TIMP-2 gene expression level. Thus, they suggested that Betulinic acid could be effective on cell migration, and metastasis and that it was a potential anti-cancer drug [15]. Yang et al. studied the anti-cancer activity of betulinic acid on renal cancer lines using the in vivo, and in vitro methods. Betulinic acid was shown to have increased the proliferation in the 786-O (human renal cell adenocarcinoma cell line) and ACHN cell lines, induced apoptosis and suppressed cell migration, and invasion [16]. Our study findings are consistent with Yang et al study in that betulinic acid induces apoptosis in renal cancer cell lines. Wang et al., showed in a study of breast cancer that the cells treated with paclitaxel-betulinic acid hybrid had higher rates of increase in apoptosis, and had less cell migration compared to cells exposed to only paclitaxel. Thus, they reported that betulinic acid positively increased the effectiveness of paclitaxel, an anticancer drug [17]. Gao et al., reported in their study on breast cancer cell lines that the typical morphological features of apoptosis occurred after betulinic acid treatment, which induced the apoptosis [18].

The present study confirmed that betulinic acid was able to promote apoptosis in renal cell carcinoma cells. Our results showed that the ratio of apoptotic cell death in ACHN, and CAKI-2 cell lines were increased compared to the numbers in MRC-5 healthy cell line. In addition, we observed that the nuclear enrichment factor levels as an indicator of apoptotic cells in ACHN, and CAKI-2 cell lines were higher compared with the MRC-5 healthy cell line, and control cells. Caspase 3/BCA activity as a marker of apoptosis has also increased in ACHN, and CAKI- 2 cell lines compared to the numbers in MRC-5.

In conclusion, we found with the results of Annexin- $\mathrm{V}$, apoptosisrelated nucleosomal enrichment factor levels measurement and Caspase 3/BCA activity that betulinic acid triggered apoptosis in both renal cancer cell lines, particularly through the caspase 3 activity.

Acknowledgements/Funding: This work was supported by Scientific Research Projects Coordination Unit of Istanbul University. Project number 23450

\section{Compliance with Ethical Standards}

Ethical approval: According to the Institutional Ethical Committee this study did not require ethics approval as it was conducted on cell lines and the data did not contain patientspecific information. (Document number: 1566/23 12 2019)

Conflict of Interest: All the authors have declared no competing interest.

Authors' Contributions: AE: writing and supervisor; ESI: writing and cell culture procedures; BE, MNA and GK, : Cell culture procedures; BC: Statistical analysis

\section{REFERENCES}

[1] Phillips DR, Rasbery JM, Bartel B, Matsuda SP. Biosynthetic diversity in plant triterpene cyclization. Curr Opin Plant Biol 2006; 9:305-14. doi: 10.1016/j.pbi.2006.03.004

[2] Cmoch P, Pakulski Z, Swaczynova J, Strnad M. Synthesis of lupane-type saponins bearing mannosyl and 3,6-branched trimannosyl residues and their evaluation as anticancer agents. Carbohydr Res 2008; 343: 995-1003. doi: 10.1016/j. carres.2008.02.011.

[3] Zhang X, Hu J, Chen Y. Betulinic acid and the pharmacological effect of tumor supressions. Mol Med Rep 2016; 14:4489 - 95. doi: $10.3892 / \mathrm{mmr} .2016 .5792$.

[4] Fulda S, Scaffidi C, Susin SA, et al. Activation of mitochondria and release of mitochondrial apoptogenic factors by betulinic acid. J Biol Chem 1998; 273:33942-48. doi: 10.1074/ jbc.273.51.33942

[5] Fulda S, Galluzzi L, Kroemer G. Targeting mitochondria for cancer therapy. Nat Rev Drug Discov 2010; 9:447-64. doi: $10.1038 / \mathrm{nrd} 3137$.

[6] Fulda S. Targeting apoptosis for anticancer therapy. Semin Cancer Biol 2015; 31:84-88. doi: 10.1016/j. semcancer.2014.05.002.

[7] Hsu TI, Wang MC, Chen SY, et al. Betulinic acid decreases specificity protein $1(\mathrm{Sp} 1)$ level via increasing the sumoylation of Sp1 to inhibit lung cancer growth. Mol Pharmacol 2012; 82:1115-28. doi: 10.1124/mol.112.078485.

[8] Struh CM, Jager S, Schempp CM, Scheffler A, Martin SF. A novel triterpene extract from mistletoe induces rapid apoptosis in murine B16.F10 melanoma cells. Phytother Res 2012; 26:1507-12. doi: 10.1002/ptr.4604.

[9] Soica C, Danciu C, Savoiu-Balint G, et al. Betulinic acid in complex with a gamma-cyclodextrin derivative decreases proliferation and in vivo tumor development of nonmetastatic and metastatic B164A5 cells. Int J Mol Sci 2014; 15:8235-55. doi: 10.3390/ijms15058235. 
[10] Wang $\mathrm{P}, \mathrm{Li}$ Q, Li K, et al. Betulinic acid exerts immunoregulation and anti-tumor effect on cervical carcinoma (U14) tumorbearing mice. Pharmazie 2012; 67:733-9. doi.org/10.1691/ ph.2012.1822

[11] Kowalczyk T, Sitarek P, Skała E, et al. Induction of apoptosis by in vitro and in vivo plant extracts derived from Menyanthes trifoliata L. in human cancer cells. Cytotechnology 2019; 71:165-80. doi: 10.1007/s10616.018.0274-9.

[12] Zhao Z, Wang J, Tang J, et al. JNK and Akt-mediated Puma expression in the apoptosis of cisplatin-resistant ovarian cancer cells. Biochem J. 2012; 444: 291-301. doi: 10.1042/ BJ20111855.

[13] Li L, Du Y, Kong X, et al. Lamin B1 is a novel therapeutic target of betulinic acid in pancreatic cancer. Clin Cancer Res 2013; 1:4651-61. doi: 10.1158/1078-0432.CCR-12-3630.

[14] Saeed MEM, Mahmoud N, Sugimoto Y, Efferth T, AbdelAziz H. Betulinic Acid Exerts Cytotoxic Activity Against Multidrug-Resistant Tumor Cells via Targeting Autocrine
Motility Factor Receptor (AMFR). Front Pharmacol. 2018; 9:481. doi: 10.3389/fphar.2018.00481.

[15] Zeng A, Hua H, Liu L, Zhao J. Betulinic acid induces apoptosis and inhibits metastasis of human colorectal cancer cells in vitro and in vivo. Bioorg Med Chem 2019;27:2546-52. doi: 10.1016/j.bmc.2019.03.033.

[16] Yang C, Li Y, Fu L, Jiang T, Meng F. Betulinic acid induces apoptosis and inhibits metastasis of human renal carcinoma cells in vitro and in vivo. J Cell Biochem 2018;119:8611-22. doi: $10.1002 /$ jcb.27116.

[17] Wang R, Yang M, Li G, et al. Paclitaxel-betulinic acid hybrid nanosuspensions for enhanced anti-breast cancer activity. Colloids Surf B Biointerfaces 2019;174:270-9. doi: 10.1016/j. colsurfb.2018.11.029.

[18] Gao Y, Ma Q, Ma YB, et al. Betulinic acid induces apoptosis and ultrastructural changes in MDA-MB-231 breast cancer cells. Ultrastruct Pathol 2018;42:49-54. doi: 10.1080/01913.123.2017.1383548. 